\title{
Abortions followed by contraceptive failures in Northern India: an analysis of contraceptive histories (2009-2014)
}

\author{
Anjali Singh ${ }^{1 *}$, Rakesh Mishra ${ }^{2}$, K. K. Singh ${ }^{1}$ and Prashant Verma ${ }^{3}$
}

\author{
* Correspondence: anjali.chhaya28@ \\ gmail.com \\ ${ }^{1}$ Department of Statistics, Institute \\ of Science, Banaras Hindu \\ University, Varanasi, UP 221005, \\ India \\ Full list of author information is \\ available at the end of the article
}

\begin{abstract}
This study tries to elicit the unexplored nexus between the contraceptive failure and abortions in India's most populous state Uttar Pradesh. Condom being the most used modern method contributes to $47 \%$ of all observed episodes in the calendar period. Of all accidental pregnancies occurred because of modern contraceptive failures, 35.2\% terminated with induced abortions. Gross failure rate of modern methods is conspicuously higher for urban poor, uneducated women, and marginalized section of population living in urban area. From a total of 7496 episodes of all reversible methods, abortions are estimated as high as 29.2\%, whereas for the traditional method it accounts for around $21 \%$. The empirical evidence of induced abortions due to contraceptive failure put serious concern regarding unintended pregnancies and hence discourages fertility intentions among the potential couples.

Keywords: Contraceptive discontinuation, Gross failure rate, Unintended pregnancy, Abortions, Weibull regression
\end{abstract}

\section{Introduction}

Abortions being a proximate determinant of fertility are a critical component to the women's reproductive right (Johnston, 2004; Bongaarts \& Feeney, 1998; Gupte et al., 1997). Several developed and developing countries have liberalized their abortion policies in the recent past (Bongaarts \& Westoff, 2000; Mathai, 1997). The impression behind the introduction of abortion as an aid to societal changes was to ensure minimal morbidities and mortality among pregnant women during risky circumstances (Retherford \& Roy, 2003). The Indian government introduced the Medical Termination of Pregnancy (MTP) Act in 1971 with an allowance of abortions under some restricted provisions to safeguard women reproductive rights (Government of India, 1971, 2002 $\&$ 2003). The present estimates of the abortion statistics in India put forward worrisome evidences. The recent figures published by the Ministry of Health and Family Welfare report a total of 0.7 million annual abortions in India during 2015-16 (Government of India, 2016). However, a study conducted by Singh et al. (2018) acclaims a total of 15.6 million annual abortions in India in 2015, out of which 3.4 million were

(c) The Author(s). 2020 Open Access This article is licensed under a Creative Commons Attribution 4.0 International License, which permits use, sharing, adaptation, distribution and reproduction in any medium or format, as long as you give appropriate credit to the original author(s) and the source, provide a link to the Creative Commons licence, and indicate if changes were made. The images or other third party material in this article are included in the article's Creative Commons licence, unless indicated otherwise in a credit line to the material. If material is not included in the article's Creative Commons licence and your intended use is not permitted by statutory regulation or exceeds the permitted use, you will need to obtain permission directly from the copyright holder. To view a copy of this licence, visit http://creativecommons.org/licenses/by/4.0/. 
facility-based abortions. A massive difference between these two estimates creates confusion regarding the reliability of abortion estimates in India. Reasonably, due to the lack of comprehensive estimation mechanism and larger abortions taking place outside the facility settings, abortion statistics are often underestimated in developing countries including India (Johnston \& Hill, 1996; Singh, Juarez, Prada, \& Bankole, 2019). Also, the abortions performed using medical pills are not captured in any indirect standard estimation procedures (Singh, Remez, Sedgh, Kwok, \& Onda, 2018). The stigma associated with abortions also significantly affects the reporting pattern, and hence the magnitude of abortions (Cleland \& Ali, 2004; Singh et al., 2019). The disagreements concerning the proximity of abortion statistics in Indian context are raised in several studies (Mathai, 1997; Singh, Shekhar, et al., 2018). Hand in hand, a persistent attempt to understand and differentiate various dimensions of rising abortions in India is underway since past three decades (Agrahari \& Mohanty, 2015; Shekhar, Sundaram, Hussain, Pradhan, \& Kalyanwala, 2018; Singh, Shekhar, et al., 2018).

The studies also suggest that abortions and family planning (FP) are closely linked (Bongaarts \& Westoff, 2000; Marston \& Cleland, 2003; Westoff, 2012). The magnitude of abortion depends upon the establishment of FP in society. For a society with a lower prevalence of contraception but higher unmet need ${ }^{1}$, higher prevalence of contraception with lesser demand of children, and practice of ineffective method with lesser method information tends to favor higher abortion cases (Bongaarts \& Westoff, 2000; Faúndes, 2010). The significant issues relating to contraceptive prevalence in any country can be underlined into two categories. First, the unmet need for contraception and second is related to the failure of family planning methods (Westoff, 2005). Both are critical and decisive for overall contraceptive prevalence rate $^{2}$ (CPR). The failure of contraception becomes essential subject of quality assurance given the unmet need for family planning is met and outreach of FP is established (Ali \& Cleland, 1995). Therefore, it is related to the programs outreach to the people exposed to pregnancy (Westoff, 2012). Likewise, the CPR also depends on quality of the services as well. However, several studies have argued that the prevalence of contraception is not a sufficient measure to analyze the progress of FP programs even if it has comprehensive outreach (Jejeebhoy, 1991; Marston \& Cleland, 2003). The contraceptive malfunctions caused by various factors such as the adoption of inefficient methods and inconsistency in practice remained decisive to CPR. A number of studies have suggested that FP programs have consistently been criticized for not meeting the demands of care and services in many developing countries, including India (Basu, 1984; Jain, 1989). Therefore, inadequate FP care and services lead to a higher risk of unintentional pregnancies among potential users. The unwanted and mistimed pregnancies are two serious consequences of contraceptive failures, which in the majority of the cases end up in abortions (Creanga, Rajib, Saifuddin, \& Tsui Amy, 2007). Recent evidence from the study of Singh, Shekhar, et al. (2018) elicited that nearly half of the abortion taking place in India are due to unintended pregnancies. However, there is insufficient evidences that

\footnotetext{
${ }^{1}$ Unmet need for family planning is defined as inability to use FP among the women who deliberately wanted to delay/avoid childbearing (https://dhsprogram.com/Topics/Unmet-Need.cfm).

${ }^{2}$ The percent of women belong to reproductive age (15-49 years) group who are currently using (or whose partner is using) a family planning method to limit or space their fertility is define as contraceptive prevalence rate (CPR).
} 
can describe these unintended pregnancies are the consequence of contraceptive failure. The complex contraceptive calendar data and lack of linkage between induced abortions and contraceptive failure within the same data set have delimited such investigations in India (Agrahari \& Mohanty, 2015).

It is believed that a couple aspires to adopt FP to avoid extra burden of children and to postpone the timing of birth. However, unintended pregnancies and abortions due to failure of the contraception not only discourage the intentions of use but also affect the social and economic wellbeing of the family. Despite severe consequence of unintended pregnancies and abortion on the health of women, the association between contraceptive failures and abortions is not much researched in India and holds no substantive literature at the sub-national level. Nevertheless, one could draw inferences based on the experiences of developed and developing countries. Numerous studies have manifested for a sizeable number of mistimed and united pregnancies borne out of contraceptives failure in both developed and developing countries (Cleland \& Ali, 2004; Shah \& Ahman, 2010; Singh, Remez, et al., 2018). In a study, Finer and Henshaw (2006) demonstrated that $20 \%$ of the contraceptive failure in the USA resulted in induced abortions. This estimate has increased to nearly 50\% in recent time. Jones (2018), in her recent study, showed that nearly $50 \%$ of the women who experienced induced abortions were using some form of contraception. Initially, the quantum of abortions was notably lower in developing countries compared to developed countries. Cleland and Ali (2004) reported that nearly 15\% of the contraceptive failure in developing countries resulted in mistimed and unwanted pregnancies. The low abortions rates were due to higher reliance on highly effective methods such as hormonal methods and sterilization. However, the adoption of modern contraception and the likelihood of abortions increased hand in hand over time in many developing countries. Bradley, Croft, and Rutstein (2011), in their seminal work, noticed that one in every three pregnancies in twenty developing countries was due to the contraceptive failure. Out of these pregnancies, nearly $34 \%$ resulted in induced abortions. It was repeatedly reasoned that reliance on traditional methods leads to higher failure and hence is leading to abortions (Creanga et al., 2007; Jones, 2018; Wang, Yan, \& Feng, 2004). Researches also revealed that rates of induced abortions were more eminent among women who had a limited choice of FP and low possibility of switching to other methods (Black, Gupta, Rassi, \& Kubba, 2010).

In the light of above discussion and gaps in research in India, this study aims to understand and differentiate the contraceptive use dynamics, corresponding failure cases, and subsequent abortions based on continuous contraceptive calendar data from Measurement Learning and Evaluation (MLE) survey in Uttar Pradesh. Uttar Pradesh constituting $17 \%$ in India's population stands out as the most populous state. It is also positioned fifth in the world order replacing Brazil in terms of population size (Srivastava et al., 2012). The MLE survey covers comprehensive calendar information on family planning use dynamics, reasons for discontinuation ${ }^{3}$ method failure, and consequent abortions. This offers an opportunity to conduct an in-depth exercise in urban UP, which has observed continuous increase in contraceptive usages in past few decades.

\footnotetext{
${ }^{3}$ Contraceptive discontinuation is defined as proportion of women belong to reproductive age group (15-49 years) start using a method and then stopping it for any reason while still at the risk of pregnancy.
} 
The contraceptive prevalence has increased in UP from a low of $27 \%$ in NHFS-II (1998-99) to 44\% in NFHS-III (2005-06) indicating a substantial increase in CPR between two rounds (IIPS \& Macro International, 2007). Further, an increase of $2 \%$ in CPR is also registered in past one decade from NFHS-III (2005-06) to NFHS-IV (2015-16) (IIPS and ICF, 2017). Besides this, a marginal decline of $0.7 \%$ in family planning uses in urban UP during past 10 years followed by induced abortion higher than the national average (3.4\%) indicates that all is not well with the family planning in urban Uttar Pradesh. It is further noted that a significant percentage (37\%) of users withdraw or discontinue from using family planning in Uttar Pradesh within just 12 months (IIPS and ICF, 2017). Though NFHS can reasonably demonstrate various aspects of family planning in urban UP like prevalence, discontinuations, and corresponding failure of contraception. However, it is fairly complex to estimate cases of induced abortions occurred due to contraceptive failure form the survey (Agrahari \& Mohanty, 2015). Thus, this study uses the underutilized section of calendar data from the MLE survey that maintains calendar columns for different method mix and following reasons of discontinuations, and information on abortions for both urban poor and non-poor in six bigger districts of Uttar Pradesh. The study is classified into two sections. The first section deals with the contraceptive failure dynamics and its associated determinants, whereas the second section is related to the incidence of abortions based on the former cases of contraceptive failures.

\section{Methods and materials}

\section{Data source}

The study is designed on the recent wave of Measurement Learning and Evaluation (MLE) project for the evaluation of Urban Health Initiative, which was conducted by FHI360 in collaboration with the Bill \& Melinda Gates Foundation. India is among the four countries where MLE survey was operated beside Kenya, Nigeria, and Senegal. A hybrid mechanism of study constituting the combination of both longitudinal and cross-section has been implemented in the MLE survey, where URHI introduced the intervention regarding the family planning for the selected countries (Nanda, Achyut, Mishra, \& Calhoun, 2011). Samples in India were taken from six major cities in Uttar Pradesh, namely, Agra, Aligarh, Allahabad, Gorakhpur, Moradabad, and Varanasi. The baseline survey was conducted in the concerned cities in 2010 where 17,643 currently married of reproductive age 15-49 years were interviewed. Followed by this, a midterm assessment in 2012 was done, and the end line of the survey was performed between December 2013 and July 2014. A total of 14,043 women of the reproductive ages were successfully interviewed in the end line of the survey.

For analysis, the retrospective details of monthly uses of various family planning methods have been segregated from a complicated string variable containing detailed information on contraceptive use dynamics. Contraceptive and reproductive history of all ever-married women have been compiled for 5 years and 7 months prior to the end line survey (July 2014). The calendar of reproductive dynamics, contraceptive uses, sources of family planning, and reasons of discontinuation for each episode are restructured and positioned in the three subsequent columns. The duration of uninterrupted use of contraceptive is decided by continuous episodes or segments of FP methods. 
These episodes are further used as a unit of analysis. The present study includes only those women who had experienced at least one such episode of any reversible methods. The calendar data consist of 67 rows of each month starting from July 2014 to January 2009. The episodes started before the calendar period of January 1, 2009 are treated as left censored episodes and excluded from the data because the exact length of use is not known. The episodes of the last 3 months before the survey are also excluded to eliminate the possibility of underestimating failure rate because of the underreporting of first quarter of pregnancy. After putting these restrictions, data used in the present study is confined to 3-66 months preceding the survey and includes a total of 7496 episodes of all reversible methods (modern or traditional). The right-censored episodes which were not ended before 3 months prior to the survey date are also included in the analysis.

\section{Variables}

\section{Dependent variable}

As mentioned in the data section, the calendar module records the reasons for disruption of contraceptive use. There were nineteen reasons coded in the MLE questionnaire for discontinuation of the FP methods, and one of them is "Method failed/Became pregnant while using." The study primarily focused on those episodes ended to accidental pregnancies are termed as "Contraceptive failure." Additionally, abortions followed by the failure of the modern reversible and traditional method are also taken up in this study. Thus, in this study, the likelihood of induced abortions is mainly confined to the contraceptive failure cases.

\section{Independent measure}

A list of background socioeconomic and demographic covariates is included in the analysis. The socioeconomic variables such as user's educational attainment, caste, religion, place of residence, and wealth status are treated as fixed covariates and taken at the time of interview. The demographic variables such as age, number of children, and desired level of users are computed at the end of the episode and called as time-varying covariates. Unlike others, the source of supply was measured at the start of an episode. More detail information of these explanatory variables is given in Table 1.

\section{Methodology}

The variations in the failure rate by methods of contraception are affected by different reasons of discontinuations, and make the comparison of failure rate difficult across population. For resolving this issue, an "Associated Single Decrement Life Table" (ADLT) approach is used for the analysis. According to this approach, failure of a method is considered the only cause for discontinuing it. It indicates that a woman will discontinue using the method only because the method fails while using it and she becomes pregnant; all the other competing reasons are eliminated from the analysis by treating them as a censored observation. The cumulative probabilities of failure estimated from life table are called "Gross Failure Rate" (GFR). For establishing the association between the failure function and the independent variables which were used in the life table analysis, Wilcoxon test has been performed to test the equality of survival 
Table 1 Descriptive statistics of the sample variables included in the study

\begin{tabular}{|c|c|c|c|c|}
\hline \multirow[t]{2}{*}{ Variable } & \multirow[t]{2}{*}{ Category } & \multirow{2}{*}{$\begin{array}{l}\text { All } \\
\text { reversible } \\
\text { method } \\
\text { Mean }\end{array}$} & \multirow{2}{*}{$\begin{array}{l}\text { Condom } \\
\text { Mean }\end{array}$} & \multirow{2}{*}{$\begin{array}{l}\text { Traditional } \\
\text { method } \\
\text { Mean }\end{array}$} \\
\hline & & & & \\
\hline \multirow[t]{6}{*}{ No of living children } & \multirow[t]{2}{*}{ At most one child } & 0.29 & 0.34 & 0.28 \\
\hline & & $(2185)$ & (1194) & $(651)$ \\
\hline & \multirow[t]{2}{*}{$2-3$} & 0.51 & 0.50 & 0.48 \\
\hline & & (3819) & $(1781)$ & $(1127)$ \\
\hline & \multirow[t]{2}{*}{$4 \& 4+$} & 0.20 & 0.16 & 0.25 \\
\hline & & $(1492)$ & $(567)$ & $(584)$ \\
\hline \multirow[t]{6}{*}{ Desire level for children } & \multirow{2}{*}{$\begin{array}{l}\text { Greater than desire (no. of living } \\
\text { children-desire no. of children }>0 \text { ) }\end{array}$} & 0.29 & 0.26 & 0.33 \\
\hline & & $(2199)$ & (922) & $(780)$ \\
\hline & \multirow{2}{*}{$\begin{array}{l}\text { Equal to desire (no. of living } \\
\text { children-desire no. of children =0) }\end{array}$} & 0.40 & 0.39 & 0.38 \\
\hline & & (2999) & $(1364)$ & (895) \\
\hline & \multirow{2}{*}{$\begin{array}{l}\text { Lower than desire (no of living } \\
\text { children-desire no. of children < 0) }\end{array}$} & 0.29 & 0.35 & 0.29 \\
\hline & & (2298) & $(1256)$ & $(687)$ \\
\hline \multirow{6}{*}{$\begin{array}{l}\text { Source of supply (place from which } \\
\text { respondent get contraceptive) }\end{array}$} & \multirow[t]{2}{*}{ Public medical sector } & 0.09 & 0.05 & --- \\
\hline & & $(661)$ & $(167)$ & --- \\
\hline & \multirow[t]{2}{*}{ Private medical sector } & 0.34 & 0.41 & ---- \\
\hline & & $(2516)$ & $(1436)$ & ---- \\
\hline & \multirow[t]{2}{*}{ Husband/relatives/friends } & 0.58 & 0.55 & --- \\
\hline & & $(4319)$ & (1939) & --- \\
\hline \multirow[t]{6}{*}{ Age at the end of the episode } & \multirow[t]{2}{*}{$<25$} & 0.16 & 0.17 & 0.15 \\
\hline & & $(1195)$ & $(602)$ & $(350)$ \\
\hline & \multirow[t]{2}{*}{$25-34$} & 0.52 & 0.54 & 0.47 \\
\hline & & $(3872)$ & $(1913)$ & $(1101)$ \\
\hline & \multirow[t]{2}{*}{$35-49$} & 0.32 & 0.29 & 0.39 \\
\hline & & $(2429)$ & $(1027)$ & (911) \\
\hline \multirow{8}{*}{$\begin{array}{l}\text { Woman's education (woman's years } \\
\text { of schooling) }\end{array}$} & \multirow[t]{2}{*}{ No education (0 years) } & 0.27 & 0.22 & 0.35 \\
\hline & & $(2010)$ & (773) & $(837)$ \\
\hline & \multirow[t]{2}{*}{ Primary ( $1-5$ years) } & 0.11 & 0.10 & 0.13 \\
\hline & & (852) & (366) & $(310)$ \\
\hline & \multirow[t]{2}{*}{ Secondary (6-10 years) } & 0.38 & 0.40 & 0.33 \\
\hline & & $(2832)$ & $(1409)$ & $(781)$ \\
\hline & Higher than secondary (11+ years) & 0.24 & 0.28 & 0.18 \\
\hline & & $(1802)$ & (994) & $(434)$ \\
\hline Wealth index & Poorest & 0.18 & 0.12 & 0.24 \\
\hline & & $(1330)$ & $(454)$ & $(576)$ \\
\hline & Poorer & 0.18 & 0.17 & 0.20 \\
\hline & & $(1376)$ & (599) & $(478)$ \\
\hline & Middle & 0.21 & 0.22 & 0.20 \\
\hline & & (1575) & (793) & (464) \\
\hline & Richer & 0.22 & 0.24 & 0.19 \\
\hline & & $(1681)$ & (857) & (453) \\
\hline & Richest & 0.20 & 0.24 & 0.17 \\
\hline & & (1534) & (839) & (391) \\
\hline
\end{tabular}


Table 1 Descriptive statistics of the sample variables included in the study (Continued)

\begin{tabular}{|c|c|c|c|c|}
\hline \multirow[t]{2}{*}{ Variable } & \multirow[t]{2}{*}{ Category } & \multirow{2}{*}{$\begin{array}{l}\text { All } \\
\text { reversible } \\
\text { method } \\
\text { Mean }\end{array}$} & \multirow{2}{*}{$\begin{array}{l}\text { Condom } \\
\text { Mean }\end{array}$} & \multirow{2}{*}{$\begin{array}{l}\text { Traditional } \\
\text { method } \\
\text { Mean }\end{array}$} \\
\hline & & & & \\
\hline \multirow[t]{6}{*}{ Caste } & $\mathrm{SC} / \mathrm{ST}$ & 0.17 & 0.16 & 0.20 \\
\hline & & $(1327)$ & $(566)$ & (498) \\
\hline & $\mathrm{OBC}$ & 0.49 & 0.49 & 0.50 \\
\hline & & $(3695)$ & $(1730)$ & $(1194)$ \\
\hline & Other & 0.33 & 0.36 & 0.30 \\
\hline & & $(2474)$ & $(1246)$ & (670) \\
\hline \multirow[t]{2}{*}{ Religion } & Muslim & 0.31 & 0.36 & 0.27 \\
\hline & & $(2336)$ & $(1283)$ & (647) \\
\hline \multirow[t]{2}{*}{ Residence } & Slum & 0.51 & 0.50 & 0.51 \\
\hline & & $(3841)$ & $(1778)$ & (1204) \\
\hline \multirow[t]{8}{*}{ Migration } & Same city/different house & 0.58 & 0.57 & 0.57 \\
\hline & & $(4323)$ & $(2032)$ & $(1348)$ \\
\hline & Intra state (city) & 0.20 & 0.24 & 0.16 \\
\hline & & $(1525)$ & $(833)$ & (374) \\
\hline & Intra state (village) & 0.17 & 0.14 & 0.22 \\
\hline & & $(1245)$ & $(483)$ & (529) \\
\hline & Inter-state (city/village) & 0.05 & 0.05 & 0.05 \\
\hline & & $(403)$ & (194) & (111) \\
\hline
\end{tabular}

Values in the parenthesis are observations

among the different groups and variables. To evaluate the relationship between the covariates and hazard of 1-year failure rate of all reversible methods, condom, and traditional methods, Weibull AFT models are used (Ali, Marshall, \& Babiker, 2001). The mathematical expression of the Weibull AFT model is shown below,

$$
h(t)=\delta t^{\delta-1} e^{\left(\beta_{0}+\beta_{1} X_{1}+\beta_{2} X_{2}+\beta_{3} X_{3}+\cdots \cdots \cdots \cdots+\beta_{m X_{m}}\right)}
$$

which further written as

$$
h(t)=h_{0}\left(t e^{\{X \beta\}}\right) e^{\{X \beta\}}
$$

where $h_{0}$ is the baseline hazard, $\delta$ is the shape parameter, and $\beta$ 's are coefficients of $X$ 's. The $\beta$ coefficients for the covariates are calculated with the maximum-likelihood method. The shape of the Weibull distribution gives the hazard function, i.e., either increasing or decreasing which estimated by the shape parameter $\delta$. By following these failure cases, one can gather the information about all outcomes ended in induced abortions which provide a basis for estimating the next objective of this paper. The descriptive analysis of these cases is calculated in relation to contraceptive methods.

Furthermore, a multivariate binary logistic regression has been applied to examine the effect of the family planning methods and aforementioned socioeconomic and demographic variables on induced abortion (considered as a dependent variable). The outcome of contraceptive failure in last 5 years preceding the end line survey is treated as dependent variable and classified into two categories: first is coded as "1" if 
unintended pregnancies terminate to induced abortions and the second is coded as " 0 " if the failure resultant in live births. All other outcomes such as miscarriages or stillbirths were dropped from the study. The cases of abortion from failure cases assume non-linear relation; hence, binary logistic regression models are applied in such conditions (Retherford \& Choe, 1993). The model for the logistic regression is given as

$$
\log \left(\frac{P}{(1-P)}\right)=\beta_{o}+\beta_{1} x_{1}+\beta_{2} x_{2}+\ldots+\beta_{k} x_{k}+\epsilon_{i j}
$$

where $x_{1}, x_{2}, x_{3} \ldots, x_{\mathrm{k}}$ are $k$ independent covariates, and $P$ stands for the probability of occurrences of induced abortions from the method failures. $\beta_{i} \mathrm{~s}$ are the regression coefficient associated with the $x_{\mathrm{i}} \mathrm{s}$, and $\beta_{o}$ is the intercept.

\section{Results}

\section{Descriptive statistics}

Table 1 presents the mean number of episodes according to women's selected socioeconomic and demographic characteristics. Findings elucidate that the couples with 23 living children have a higher need for FP. Also, women with a number of children (or a fertility level) higher than the desired one are using lesser reversible and traditional methods. The share of episodes of all reversible methods and condoms for women with four or higher parity is low, which indicates lesser use of modern methods over traditional methods. Surprisingly, the husband, friends, or relatives are reported as the prominent source of modern contraceptive supply, while public sectors are hardly utilized for the same. Users of age 35 years and above have inclination for traditional methods. However, the users aged 25-34 years offered higher proportion of use of condom and modern reversible methods. This trend is also similar for users of young age groups (15-24 years).

The distribution of the contraception among users of different socioeconomic backgrounds shows the popularity of different methods among them. Conspicuously, the episodes of contraception are affected by the economic status of the users. Users belong to the poorest economic group, rely mainly on traditional methods, whereas the practice of family planning methods among middle and richer households are unlike each other. Education is also one of the determining factors of the uses of different types of contraceptive methods. The results show that illiterate women are the segment that relies the most on traditional methods, compared to the other educational groups. Among the socio-religious groups, Other Backward Caste $^{4}(\mathrm{OBC})$ and non-Muslims have reported higher episodes of reversible methods and condoms.

The findings also suggest that the prevalence of any kind of reversible methods, condom, and traditional method is higher in slum areas. Finding indicates that the intrastate migrants who migrated from villages to urban centers of the Uttar Pradesh mostly practice traditional methods. However, the adoption of reversible methods and condom increases with the higher exposure to the urban areas as the propensity of use of condom is much higher among the urban to urban migrants. The practice of three distinct

${ }^{4}$ Other Backward Caste $(\mathrm{OBC})$ which is a collective term used by the Government of India to classify castes which are socially and educationally disadvantaged 
categories of FP methods is equally established among migrants who move within the same urban center.

\section{Level of contraceptive failure rate by methods}

Table 2 shows the associated decrement life table (ADLT) estimates of method-specific gross failure rate (GFR) for three different durations of contraceptive use viz. 12 months, 24 months, and 36 months respectively. Conspicuously, the GFR for all reversible methods indicate a total of $2.8 \%$ discontinued episodes due to method failure within 12 months of exposure. It cumulatively adds up to $7.1 \%$ with an exposure of 3 years with the higher incidences of failure during the second year. Both the traditional and modern methods are withdrawn due to the failure of episodes within the 2 years of exposure with many failures in the first year of exposure. This indicates that the practice of traditional methods for long duration is more susceptible to failure or unintended pregnancies. Among traditional FP methods, withdrawal method appears riskier for the users to safeguard unwanted pregnancies. Contradictory to other modern family planning methods, consumption of pills has a comparatively higher gross failure rate between the second and third month of exposure.

The failure of IUD/PPIUD method is noticeably very low with respect to other modern and traditional methods. However, the condoms and pills have similar GFR in the exposure period of 3 years but in short duration, condoms have higher failure cases. Thus, the GFRs of all reversible FP methods at segregated levels ascertain for a substantial variation by method choices and duration of use. The extent of contraceptive use, discontinuation, switching, and failure are profoundly determined by method information, service factors, outreach, and user characteristics (Hossain \& Phillips, 1996; Jain, 2017; Singh, Singh, \& Verma, 2016; Zhang, Tsui, \& Suchindran, 1999). Along with demand-side factors, the reproductive status of the woman, place of residence, education attainment, socio-religious belonging, and household economic status are critical components in the adoption of FP (Oddens \& Lehert, 1997).

Table 2 Life table 12-month contraceptive failure per 100 episodes for different methods

\begin{tabular}{|c|c|c|c|c|c|c|}
\hline \multirow[b]{2}{*}{ Methods } & \multicolumn{3}{|c|}{ Gross failure rate (GFR) } & \multicolumn{3}{|c|}{ Difference in rates } \\
\hline & $\begin{array}{l}\text { First year of use } \\
\text { (12 months) }\end{array}$ & $\begin{array}{l}\text { Second year of use } \\
\text { ( } 24 \text { months) }\end{array}$ & $\begin{array}{l}\text { Third year of use } \\
\text { (36 months) }\end{array}$ & $\begin{array}{l}24 \text { vs. } 12 \\
\text { months }\end{array}$ & $\begin{array}{l}36 \text { vs. } 24 \\
\text { months }\end{array}$ & $\begin{array}{l}36 \text { vs. } 12 \\
\text { months }\end{array}$ \\
\hline $\begin{array}{l}\text { All reversible } \\
\text { method }\end{array}$ & 2.80 & 5.14 & 7.08 & 2.34 & 1.94 & 4.28 \\
\hline $\begin{array}{l}\text { Modern } \\
\text { reversible } \\
\text { method }\end{array}$ & 2.62 & 4.44 & 6.13 & 1.82 & 1.69 & 3.51 \\
\hline $\begin{array}{l}\text { Traditional } \\
\text { method }\end{array}$ & 3.17 & 6.48 & 8.82 & 3.31 & 2.34 & 5.65 \\
\hline IUD/PPIUD & 0.54 & 1.05 & 1.05 & 0.51 & 0.00 & 0.51 \\
\hline Pill & 2.46 & 4.64 & 7.09 & 2.18 & 2.45 & 4.63 \\
\hline Condom & 3.15 & 5.14 & 7.01 & 1.99 & 1.87 & 3.86 \\
\hline Rhythm & 3.13 & 5.89 & 8.11 & 2.76 & 2.22 & 4.98 \\
\hline Withdrawal & 3.23 & 8.76 & 11.65 & 5.53 & 2.89 & 8.42 \\
\hline
\end{tabular}

Source: Authors' estimations from calendar data. \# = all reversible method includes both modern and traditional methods 


\section{Socioeconomic and demographic differentials of contraceptive failure rate}

To understand and differentiate the gross effect of selected background factors on the failure of episodes of FP methods, the annual failure rate separately for all reversible methods, traditional methods, and condom have been worked and results in terms of GFR are presented in Table 3. The results offer a significant variation in the number of episodes adopted and discontinued due to failure among the method mix of FP. For this study, a 12-month exposure for failure cases is taken into consideration to avoid the recall issues.

Contraceptive use dynamics are highly associated with the fertility desires and age of exposure to births. Thus, failure of contraception for all reversible methods, condom, and traditional methods is higher among women of age less than 25, with single child, and unfulfilled desire for the completed family size. The women practicing traditional methods with at least one birth and with achieved fertility lower than the desired level are at higher risk of contraceptive failure. It is further noted that the women with higher parity and completed desire of birth mainly use condoms and therefore, the cases of condom failure are maximum among them.

Further, among the socio-religious groups, $\mathrm{OBC}$ and Muslims have significantly higher GFR than their counterparts for all reversible methods and condoms in particular. In addition to the individual desire and socio-religious background of the users, the source of supply is also a crucial factor for failure of contraceptives assessed for 12month duration. Condoms or other reversible methods obtained from public sources have notably higher gross failure rates (Zhang et al., 1999). Besides source of contraception, education of the women plays crucial role in administering methods suitability and consequent side effects such as unintended pregnancies and abortions. A monotonic decreasing relationship is recognized between education of mother and contraceptive failure for all reversible methods and traditional methods, except for primary educated women which have highest failure rate.

Users with secondary or higher education level have significantly low failure episodes of all reversible and traditional methods. A similar inverse association is also manifested between household's wealth status and contraceptive failure for all reversible methods and condoms at the gross level. Besides poor in Uttar Pradesh, the user's living in slum areas of select districts has significantly higher GFR of all reversible methods, condoms, and traditional methods. Also, the intra-state migrants who migrated from rural areas to urban centers of select districts have higher GFR for traditional methods, which is mainly because of higher adoption of traditional methods. However, this finding is statistically insignificant. The intra-state urban to urban migrants also have significantly higher GFR for all three categories of contraception.

\section{Weibull regression analysis}

In addition to verify whether the variation in method-specific GFR depicted by the different levels of explanatory variables is statistically significant or not and to measure the effect of these socioeconomic and demographic covariates on accidental pregnancies caused by failure of contraception has been worked out through Weibull regression. The regression results in terms of hazard ratio are reported in Table 4. The risk of experiencing an accidental pregnancy decreased monotonically with higher parity for 
Table 3 Life table failure rates for all reversible method, traditional method, and condom by selected background characteristics of users, Uttar Pradesh

\begin{tabular}{|c|c|c|c|}
\hline Characteristics & All reversible method & Condom & Traditional method \\
\hline \multicolumn{4}{|l|}{ No. of living children } \\
\hline At most one child & $5.58^{*}$ & $4.52^{*}$ & $8.15^{*}$ \\
\hline $2-3$ & $1.90^{*}$ & $2.49^{*}$ & $2.00^{*}$ \\
\hline $4 \& 4+$ & $0.99^{*}$ & $2.34^{*}$ & $0.00^{*}$ \\
\hline \multicolumn{4}{|l|}{ Desire level } \\
\hline Greater than desire & $1.18^{*}$ & $2.52^{*}$ & $0.15^{*}$ \\
\hline Equal to desire & $1.70^{*}$ & $2.16^{*}$ & $1.91^{*}$ \\
\hline Lower than desire & $5.60^{*}$ & $4.59^{*}$ & $8.48^{*}$ \\
\hline \multicolumn{4}{|l|}{ Source of supply } \\
\hline Public medical sector & $3.46^{*}$ & $8.05^{*}$ & -- \\
\hline Private medical sector & $2.01^{*}$ & $2.34^{*}$ & -- \\
\hline Husband/relatives/friends & $3.16^{*}$ & $3.39^{*}$ & -- \\
\hline \multicolumn{4}{|l|}{ Age at the end of episode } \\
\hline$<25$ & $9.76^{*}$ & $10.63^{*}$ & $11.20^{*}$ \\
\hline $25-34$ & $2.31^{*}$ & $2.32^{*}$ & $3.07^{*}$ \\
\hline $35-49$ & $0.76^{*}$ & $1.02^{*}$ & $0.62^{*}$ \\
\hline \multicolumn{4}{|l|}{ Education } \\
\hline No education & $3.64^{*}$ & 4.41 & $2.88^{*}$ \\
\hline Primary & $4.18^{*}$ & 4.16 & $5.52^{*}$ \\
\hline Secondary & $2.58^{*}$ & 3.38 & $3.00^{*}$ \\
\hline Higher than secondary & $1.66^{*}$ & 1.61 & $2.41^{*}$ \\
\hline \multicolumn{4}{|l|}{ Caste } \\
\hline SC/ST & $2.80^{*}$ & 3.48 & $3.50^{*}$ \\
\hline $\mathrm{OBC}$ & $3.41^{*}$ & 3.44 & $4.04^{*}$ \\
\hline General & $1.92^{*}$ & 2.62 & $1.49^{*}$ \\
\hline \multicolumn{4}{|l|}{ Religion } \\
\hline Non-Muslim & $2.37^{*}$ & $2.43^{*}$ & 3.32 \\
\hline Muslim & $3.77^{*}$ & $4.45^{*}$ & 2.78 \\
\hline \multicolumn{4}{|l|}{ Wealth index } \\
\hline Poorest & $4.47^{*}$ & $3.40^{*}$ & $5.31^{*}$ \\
\hline Poorer & $3.50^{*}$ & $5.30^{*}$ & $2.66^{*}$ \\
\hline Middle & $3.66^{*}$ & $4.63^{*}$ & $3.70^{*}$ \\
\hline Richer & $1.40^{*}$ & $1.88^{*}$ & $1.29^{*}$ \\
\hline Richest & $1.49^{*}$ & $1.55^{*}$ & $2.15^{*}$ \\
\hline \multicolumn{4}{|l|}{ Residence } \\
\hline Non-slum & 2.53 & 2.94 & 2.43 \\
\hline Slum & 3.06 & 3.36 & 3.89 \\
\hline \multicolumn{4}{|l|}{ Migration } \\
\hline Same city/different house & $2.49^{*}$ & $3.08^{*}$ & $2.66^{*}$ \\
\hline Intra-state (city) & $3.64^{*}$ & $3.83^{*}$ & $3.53^{*}$ \\
\hline Intra-state (village) & $3.38^{*}$ & $2.61^{*}$ & $5.03^{*}$ \\
\hline Inter-state (city/village) & $1.37^{*}$ & $2.36^{*}$ & -- \\
\hline
\end{tabular}

*Significant $p \leq 0.05$; according to Wilcoxon test, (--) no of observation $<125$ 
Table 4 Results from Weibull hazard regression of contraceptive failure rates within 1 year of method adoption for all methods combined traditional method and for condom, by selected characteristics of female users, Uttar Pradesh, 2009-14

\begin{tabular}{|c|c|c|c|}
\hline Characteristics & All reversible method & Condom & Traditional method \\
\hline \multicolumn{4}{|l|}{ No. of living children } \\
\hline At most one child ${ }^{\circledR}$ & 1 & 1 & 1 \\
\hline $2-3$ & $0.72^{*}[0.49,0.98]$ & $0.98[0.38,2.00]$ & $0.88[0.34,2.09]$ \\
\hline $4 \& 4+$ & $0.42[0.17,1.11]$ & $0.87[0.21,2.37]$ & $0.75[0.04,2.03]$ \\
\hline \multicolumn{4}{|l|}{ Desire level } \\
\hline Greater than desire ${ }^{\oplus}$ & 1 & 1 & 1 \\
\hline Equal to desire & $0.88[0.60,1.28]$ & $0.67^{*}[0.33,0.97]$ & $1.32[0.67,2.61]$ \\
\hline Lower than desire & $1.55^{*}[1.04,3.96]$ & $0.87[0.42,1.72]$ & $3.53^{*}[1.50,3.70]$ \\
\hline \multicolumn{4}{|l|}{ Source of supply } \\
\hline Public medical sector ${ }^{\circledast}$ & 1 & 1 & ---- \\
\hline Private medical sector & $0.6^{*}[0.29,0.94]$ & $0.28^{*}[0.13,0.63]$ & --- \\
\hline Husband/relatives/friends & $1.33[1.08,3.02]$ & $0.39[0.19,0.81]$ & ---- \\
\hline \multicolumn{4}{|l|}{ Age at the end of the episode } \\
\hline$<25^{\oplus}$ & 1 & 1 & 1 \\
\hline $25-34$ & $0.35^{*}[0.27,0.55]$ & $0.22^{*}[0.15,0.43]$ & $0.52^{*}[0.29,0.91]$ \\
\hline $35-49$ & $0.17^{*}[0.09,0.31]$ & $0.08^{*}[0.04,0.22]$ & $0.31^{*}[0.09,0.65]$ \\
\hline \multicolumn{4}{|l|}{ Education } \\
\hline No education ${ }^{\oplus}$ & 1 & 1 & 1 \\
\hline Primary & $0.88[0.62,1.26]$ & $0.98[0.57,1.68]$ & $0.92[0.55,1.52]$ \\
\hline Secondary & $0.84[0.63,1.12]$ & $0.85[0.56,1.29]$ & $0.94[0.60,1.47]$ \\
\hline Higher than secondary & $0.76[0.50,1.16]$ & $0.8[0.44,1.43]$ & $0.76[0.36,1.59]$ \\
\hline \multicolumn{4}{|l|}{ Caste } \\
\hline $\mathrm{SC} / \mathrm{ST}^{\oplus}$ & 1 & 1 & 1 \\
\hline $\mathrm{OBC}$ & $0.97[0.72,1.33]$ & $0.92[0.47,1.90]$ & $1.46[0.67,2.73]$ \\
\hline General & $0.96[0.59,1.75]$ & $0.78[0.41,1.85]$ & $0.94[0.39,1.38]$ \\
\hline \multicolumn{4}{|l|}{ Religion } \\
\hline Non-Muslim ${ }^{\oplus}$ & 1 & 1 & 1 \\
\hline Muslim & $1.59^{*}[1.11,2.29]$ & $1.55^{*}[1.10,2.29]$ & $1.65[0.91,2.98]$ \\
\hline \multicolumn{4}{|l|}{ Wealth index } \\
\hline Poorest ${ }^{\oplus}$ & 1 & 1 & 1 \\
\hline Poorer & $0.69^{*}[0.24,0.92]$ & $0.88[0.54,1.44]$ & $0.44^{*}[0.22,0.98]$ \\
\hline Middle & $0.83[0.54,1.33]$ & $0.74[0.45,1.22]$ & $0.86[0.38,1.57]$ \\
\hline Richer & $0.3^{*}[0.20,0.64]$ & $0.45^{*}[0.26,0.78]$ & $0.31^{*}[0.14,0.98]$ \\
\hline Richest & $0.37^{*}[0.22,0.78]$ & $0.49^{*}[0.26,0.91]$ & $0.44[0.13,1.10]$ \\
\hline \multicolumn{4}{|l|}{ Residence } \\
\hline Non-slum ${ }^{\oplus}$ & 1 & 1 & 1 \\
\hline Slum & $0.93[0.65,1.25]$ & $0.78[0.51,1.29]$ & $1.09[0.37,1.87]$ \\
\hline \multicolumn{4}{|l|}{ Migration } \\
\hline Same city/different house ${ }^{\oplus}$ & 1 & 1 & 1 \\
\hline Intra-state (city) & $1.55^{*}[1.07,2.13]$ & $1.53^{*}[1.09,3.45]$ & $1.34^{*}[1.04,2.54]$ \\
\hline Intra-state (village) & $0.96[0.62,1.51]$ & $0.64[0.34,1.46]$ & $1.59[0.66,2.22]$ \\
\hline Inter-state (city/village) & $0.81[0.43,1.55]$ & $0.6[0.25,2.71]$ & ----- \\
\hline Weibull parameter & $1.82^{*}[1.55,2.06]$ & $1.76^{*}[1.37,2.03]$ & $2.12^{*}[1.70,2.66]$ \\
\hline
\end{tabular}


Table 4 Results from Weibull hazard regression of contraceptive failure rates within 1 year of method adoption for all methods combined traditional method and for condom, by selected characteristics of female users, Uttar Pradesh, 2009-14 (Continued)

\begin{tabular}{llll}
\hline Characteristics & All reversible method & Condom & Traditional method \\
\hline Constant & 3.94 & 3.32 & 4.54 \\
Wald $x^{2}$ & 136.99 & 95.53 & 119.91 \\
Log likelihood & -741.87 & -379.26 & -254.59 \\
$n$ & 7496 & 3542 & 2028 \\
$p>x^{2}$ & 0.000 & 0.000 & 0.000 \\
\hline
\end{tabular}

*Significant at $p \leq 0.05^{\oplus}=$ reference category. (--) no of observation $<125$. The analysis is controlled for region of residence (districts under study)

the users of all reversible methods, traditional method, and condoms. Users with parity two or higher have a lower likelihood of experiencing failure for all spacing method as compared to nulliparous users or users who already have one child. Further, the users who have underachieved fertility have higher risk for failure cases. Notably, the chances of contraceptive failure or accidental pregnancy are nearly 3.5 times more likely among the women who have adopted traditional methods of contraception with underachieved fertility as compared to those who have achieved or overachieved fertility goals. Likewise, the risk of accidental pregnancy was 1.5 times higher among the women with underachieved fertility as compared to overachieved fertility goals but using any reversible methods of contraception. The inefficiency of public sector as source of supply of modern reversible method is one of the reasons for failure cases and similar relation is also established in the GFR of condoms (Table 3). The failure episodes were significantly higher for all reversible methods, when it is made available by the husband or other relatives. Though the woman's education attainment is not significant when controlled with other variables, but the direction of causality indicates for a monotonic decreased in the accidental pregnancies as the education of woman increases. Similar corroboration is observed in case of wealth of household as well, where the failure cases of reversible, condom, and traditional methods decline with increasing level of households' wealth.

Among the religious groups, the hazard ratio of failure of all reversible methods, condoms, and traditional method are significantly higher among Muslim as compared to non-Muslims. However, in case of social groups, GFR indicates concordance in the direction of causality for all three methods. However, the results are not significant when controlled with other socio-demographic and economic covariates. The residential segregation of select districts indicates that the risk of accidental pregnancies due to contraceptive failures among traditional users living in slums is higher than those who live in non-slum areas. This result is also not statistically significant when control with other covariates such as socioeconomic, reproductive status, and regions.

The hazard of the failure for combined modern reversible methods, condoms, and traditional methods among inter-state urban to urban migrants is $1.55,1.53$, and 1.34 respectively. The intra-state rural to urban migrants have higher but statistically insignificant hazard for traditional method of contraception. The Weibull shape parameter concerning the failure of all three categories of FP shows that the hazard of failure of the FP methods increased significantly with time of use. 


\section{Contribution of contraceptive failure to induced abortion}

Table 5 describes the count and also the percentage of episodes track from contraceptive use to failure to induced abortion. Approximately $60 \%$ of the episodes among a total of 7496 contraceptive episodes of all spacing methods were discontinued within the observation period of 64 months between 2009 and 2014. Discontinuation of 58.7\% is registered for all reversible methods, whereas, modern reversible methods have slightly higher cessation than traditional methods. Out of all modern reversible methods, pills, and condoms contribute to higher discontinued episodes. The estimates of discontinuation and failure of contraception are apparently contrasting in UP for different FP methods. Unlike discontinuation, failure of contraception is higher among traditional users who are practicing rhythm (10.0\%) and withdrawal (14.3\%) methods. Among the modern reversible methods, nearly $7 \%$ of the cases ended up with accidental pregnancies due to method failure. Expectedly, the long-acting reversible contraceptive (LARC) method like IUD/PPIUD has least failure rate but significant discontinuations. It is worth to note that the potential users in Uttar Pradesh discontinue nearly $50 \%$ of LARC method during 64 months of the observation period. The findings presented in the table pronounce evidences of the failure of both modern and traditional methods within a window period of 64 months. However, it is equally essential to understand and segregate the incidences of failure of reversible methods with respect to the exposure period.

Studies show that women adopt family planning methods for two reasons either to limit their fertility goals or to create spacing in the timing of births (Jain, 1989; Jain, 2017; Zhang et al., 1999). The occurrence of contraceptive failures not only discourages the aspiration to use contraception, but also adversely affects the physical and social wellbeing of women. Mistimed pregnancies or unwanted pregnancies also bear an economic cost. Thus, the user's unwanted pregnancies are either delivered as a live birth or ended into abortions. In this context, it becomes imperative to examine induced abortions caused by contraceptive failures.

Our analysis reveals that out of total 7496 episodes of all reversible methods, 4402 episodes are discontinued of which 356 cases are the failure cases. Out of 356 failure cases or accidental pregnancies, 104 are terminated through abortions which account

Table 5 Episodes of contraceptive use, discontinuation, failure, and subsequent experience of induced abortion, by specific contraceptive method, Uttar Pradesh, 2009-14

\begin{tabular}{|c|c|c|c|c|c|c|c|c|}
\hline \multirow[t]{2}{*}{ Methods } & \multicolumn{2}{|c|}{$\begin{array}{l}\text { Episodes used in } \\
\text { calendar data }\end{array}$} & \multicolumn{2}{|c|}{$\begin{array}{l}\text { Discontinued } \\
\text { episodes }\end{array}$} & \multicolumn{2}{|c|}{$\begin{array}{l}\text { Episodes of } \\
\text { failure }\end{array}$} & \multicolumn{2}{|c|}{$\begin{array}{l}\text { Episodes of failure ending } \\
\text { in induced abortion }\end{array}$} \\
\hline & $\overline{(N)}$ & $(\%)$ & $\overline{(n)}$ & $(\%)$ & $\overline{(n)}$ & $(\%)$ & $\overline{(n)}$ & $(\%)$ \\
\hline$\overline{\text { Pill }}$ & 662 & 8.8 & 419 & 63.3 & 31 & 7.4 & 11 & 35.5 \\
\hline IUD/PPIUD & 638 & 8.5 & 317 & 49.7 & 5 & 1.6 & 2 & 40.0 \\
\hline Condom & 3542 & 47.3 & 2120 & 59.9 & 169 & 8.0 & 60 & 35.5 \\
\hline Rhythm & 1825 & 24.4 & 1037 & 56.8 & 104 & 10.0 & 18 & 17.3 \\
\hline Withdrawal & 495 & 6.6 & 287 & 58.0 & 41 & 14.3 & 12 & 29.3 \\
\hline Modern reversible method & 5134 & 68.5 & 3053 & 59.5 & 210 & 6.9 & 74 & 35.2 \\
\hline Traditional method & 2362 & 31.5 & 1349 & 57.1 & 146 & 10.8 & 30 & 20.5 \\
\hline All reversible method & 7496 & 100 & 4402 & 58.7 & 356 & 8.1 & 104 & 29.2 \\
\hline
\end{tabular}

Source: Estimated by the authors. $N$ total episodes of contraception, $n$ refers to the subset of total episodes of contraception ending into discontinued cases, failure cases, and abortion cases 
for $29 \%$ of total failures cases. Surprisingly, out of 210 accidental pregnancies that occurred while using a modern spacing method, only 74 are ended with abortions. However, the proportion of abortions among traditional users is 20.5 , which is $15.2 \%$, lower than the modern reversible method. This result implies that the modern method users have higher chances to eliminate unintended pregnancies as compared to traditional users. Among modern spacing methods, pregnancies resulting from pills and condoms failure significantly contribute to abortions, whereas among the traditional methods, withdrawal method is highly susceptible to failure. Besides gross level variation, the failure of reversible methods and subsequent abortions are also dependent on the demographic and socioeconomic characteristics of the users along with the type of FP methods in use (Agrahari \& Mohanty, 2015; Creanga et al., 2007).

\section{Logistic regression analysis: determinants of induced abortion}

For the observation period, the risk of induced abortions is two times higher among users of condom with reference to the users of traditional method (Table 6). This result is statistically significant. Induced abortion followed by method failure is also two times higher among modern reversible method users but this result is not statistically significant. A notable differential is offered by wealth index, where the risk of abortion against accidental pregnancies is higher among users from middle and richer wealth quintiles. Similarly, the likelihood of abortion followed by contraceptive failure increases with the women's education but did not come significant in the analysis. Also, the women with underachieved fertility have significantly lower chances for aborting the accidental pregnancies as compared to the users who have overachieved fertility goals. This is also corroborated by the evidence that women with higher parity are more likely to terminate accidental pregnancies as compared to nulliparous women or women with one parity. Among all age categories, women belonging to age groups of 25-34 imparted a higher odds ratio of pregnancy terminations as compared to younger women. Beside the variables related to reproductive status, the odds ratio among religious groups show low chances of abortion among Muslims in UP. Also, the odds ratio of abortions induced by failure of contraception was higher among residents of slums and intra-state urban-urban migrants. But these results are statistically insignificant.

\section{Discussion}

This study aims to understand and differentiate the contraceptive use dynamics, corresponding failure cases, and subsequent abortions based on the continuous contraceptive calendar data from MLE survey. The findings of the study concord with the observations noticed in the previous studies (Curtis Siân \& Hammerslough, 1995; Tsui, McDonald-Mosley, \& Burke, 2010). Among the total acceptors of FP, the users who relied upon long-term spacing methods like IUD/PPIUD have experienced lesser failure rates than those who adopted short-term methods like pills and condoms (Polis et al., 2016; Sundaram et al., 2017). Users of traditional methods have experienced higher failure cases than modern methods (Agrahari \& Mohanty, 2015; Creanga et al., 2007; Sundaram et al., 2017). Though the magnitude of differentials offered for method failure is not similar to the previous studies but preserves the directions of causality (Goldman et al., 1983). 
Table 6 Logistic regression results of induced abortion by socioeconomic and demographic characteristics of women

\begin{tabular}{|c|c|c|c|c|}
\hline \multirow[t]{2}{*}{ Characteristics } & \multirow{2}{*}{$\begin{array}{l}\text { Sample size } \\
(n=286)\end{array}$} & \multirow{2}{*}{$\begin{array}{l}\text { Odds } \\
\text { ratio }\end{array}$} & \multicolumn{2}{|c|}{ Confidence interval (95\%) } \\
\hline & & & $\overline{\mathrm{LL}}$ & UL \\
\hline \multicolumn{5}{|l|}{ Method of contraception } \\
\hline Traditional ${ }^{\circledast}$ & 113 & 1 & & \\
\hline Condom & 137 & $2.16^{*}$ & 1.26 & 3.69 \\
\hline Other modern reversible methods & 36 & 2.15 & 0.95 & 4.86 \\
\hline \multicolumn{5}{|l|}{ No. of living children } \\
\hline $0-1 \oplus$ & 164 & 1 & & \\
\hline $2-3$ & 90 & $1.81^{*}$ & 1.09 & 2.76 \\
\hline $4 \& 4+$ & 32 & $2.91^{*}$ & 2.19 & 3.86 \\
\hline \multicolumn{5}{|l|}{ Desire of children } \\
\hline Greater than desire ${ }^{\circledR}$ & 48 & 1 & & \\
\hline Equal to desire & 73 & $0.49^{*}$ & 0.25 & 0.99 \\
\hline Lower than desire & 165 & $0.05^{*}$ & 0.03 & 0.12 \\
\hline \multicolumn{5}{|l|}{ Age at the end of episode } \\
\hline$<25^{\oplus}$ & 101 & 1 & & \\
\hline $25-34$ & 144 & $2.09^{*}$ & 1.31 & 3.34 \\
\hline $35-49$ & 41 & 1.56 & 0.79 & 3.08 \\
\hline \multicolumn{5}{|l|}{ Mother's education } \\
\hline No education ${ }^{\circledR}$ & 102 & 1 & & \\
\hline Primary & 34 & 1.29 & 0.64 & 2.57 \\
\hline Secondary & 108 & 1.16 & 0.71 & 1.89 \\
\hline Higher than secondary & 42 & 1.73 & 0.91 & 3.31 \\
\hline \multicolumn{5}{|l|}{ Caste } \\
\hline $\mathrm{SC} / \mathrm{ST} \top^{\oplus}$ & 56 & 1 & & \\
\hline $\mathrm{OBC}$ & 151 & 0.64 & 0.36 & 1.11 \\
\hline General & 79 & 0.94 & 0.5 & 1.76 \\
\hline \multicolumn{5}{|l|}{ Religion } \\
\hline Non-Muslim ${ }^{\circledR}$ & 178 & 1 & & \\
\hline Muslim & 108 & $0.51^{*}$ & 0.27 & 0.95 \\
\hline \multicolumn{5}{|l|}{ Wealth index } \\
\hline Poorest ${ }^{\circledR}$ & 77 & 1 & & \\
\hline Poorer & 64 & 1.79 & 0.98 & 3.3 \\
\hline Middle & 61 & $2.34^{*}$ & 1.27 & 4.3 \\
\hline Richer & 46 & $2.06^{*}$ & 1.04 & 4.1 \\
\hline Richest & 38 & 1.49 & 0.73 & 3.08 \\
\hline \multicolumn{5}{|l|}{ Residence } \\
\hline Non-slum ${ }^{\circledR}$ & 139 & 1 & & \\
\hline Slum & 147 & 1.019 & 0.67 & 1.55 \\
\hline \multicolumn{5}{|l|}{ Migration } \\
\hline Same city/different house ${ }^{\circledR}$ & 163 & 1 & & \\
\hline Intra-state (city) & 58 & 1.17 & 0.69 & 1.99 \\
\hline Intra-state (village) & 53 & 0.76 & 0.43 & 1.33 \\
\hline Inter-state (city/village) & 12 & 1.12 & 0.21 & 5.92 \\
\hline
\end{tabular}


Table 6 Logistic regression results of induced abortion by socioeconomic and demographic characteristics of women (Continued)

\begin{tabular}{lllll}
\hline Characteristics & $\begin{array}{l}\text { Sample size } \\
(n=286)\end{array}$ & $\begin{array}{l}\text { Odds } \\
\text { ratio }\end{array}$ & & \multicolumn{2}{c}{ Confidence interval (95\%) } \\
\cline { 5 - 6 } Constant & 286 & $0.36^{*}$ & 0.24 & $\mathrm{LL}$ \\
$n$ & 286 & & \\
$\mathrm{LR} x^{2}$ & 157.14 & & \\
Log likelihood & -107.08 & & \\
$p>X^{2}$ & 0.000 & & \\
Pseudo $R^{2}$ & 42.32 & & & \\
\hline
\end{tabular}

- is reference category; ${ }^{*}$ represents the significance at the $5 \%$ level, The analysis is controlled for region of residence (districts under study), LL-Lower Limit, UL-Upper Limit.

The study concludes that the risk of contraceptive failure is higher among the youngage users ( $<25$ years). It could be because of two reasons, first, the lack of correct methods' information and second, the higher dependence on reversal methods such as condoms and traditional methods. The condoms and traditional methods both are highly susceptible to failures and consequent abortions. One of the important findings noted in this study is that even though the contraceptive failure rate is lower among the women of age group 25-34 years, the chances of abortions out of failure episodes are exceptionally higher as compared to their counterparts.

Furthermore, this study also unraveled that the risks of failure for both traditional and modern reversible methods increase significantly when sustained for a longer duration. Continuous practice of traditional methods (Withdrawal \& Rhythm) may give a false sense of security to the couples without having an efficient and correct practice of traditional methods which several times lead to the unwanted pregnancies. The married and unmarried couples who practice traditional methods have higher risk of failure leading to abortions (Agrahari \& Mohanty, 2015). Condom being the most adopted reversible method has substantially higher discontinued episodes, of which, nearly $8 \%$ are due to the failure cases. Also, these discontinued episodes of condoms are associated with the higher likelihood of abortions following the failures. It is evident that apart from traditional method of contraception, condoms as mostly used modern methods also have higher chances of failures and subsequent abortions (Creanga et al., 2007; Westoff, 2005). In the context of urban Uttar Pradesh, nearly 29\% of the abortions are due to the failure of all reversible methods. This study also concludes that the incidences of abortion followed by failure of modern reversible are considerably higher than that of the traditional methods, which means that accidental pregnancies due to traditional methods end up into live births.

Majority of the failure episodes are not ended with abortion but resulted in unwanted or mistimed births. It adversely affects the fertility intentions and behavior of the users. By analyzing cases of induced abortions in relation with background characteristics of users, it was found that users of modern reversible methods including condoms have two times higher propensity of averting unwanted pregnancies when controlled for demographic, socioeconomic, and regional variations. The likelihood of failure of contraception resulting in abortion is higher among women with more than one living child and overachieved fertility desire. This indicates that the abortions are being used as an instrument of avoiding unwanted fertility in urban UP. The termination of 
accidental pregnancies by abortions are majorly adopted by the women belonging to the affluent class and educated background. When analyzed across the religions, it was worth noting that Muslim women have significantly higher gross and net failure case of both traditional and modern reversible methods, but failures of contraception among Muslims rarely end into abortion cases. In contrast, the termination of unwanted pregnancies accompanied by failure of FP is higher among non-Muslim women. The studies show that the social and cultural impediments in using modern contraceptive methods and heavy reliance on the traditional methods are significant contributor for rising abortions (Shekhar et al., 2018; Zhang et al., 1999). In case of urban Uttar Pradesh incidence of abortion is significantly higher among modern reversible methods, which raises a question on the quality of care of family planning programs. The six urban districts have higher failure cases of traditional methods for rural-urban migrants, whereas for urban to urban migrant, failure is observed across all reversible methods, condoms as well as traditional methods leading to higher accidental pregnancies among later migrant group. The results from the study show that the failure of modern reversible methods and condoms in particular have resulted into unwanted pregnancies and consequent abortions despite the improved method information and higher contraceptive prevalence in urban areas. It is an emerging threat to the potential users in modern time.

\section{Conclusion}

Adoption of FP, acclaimed as an unfinished agenda of Sustainable Development Goals (SDGs) put forwards critical challenges in front of developing countries like India, and especially in the states with low socioeconomic development such as Uttar Pradesh. UP being the most populous state in India has double burden of increasing FP services and securing quality of various reversible methods hand in hand. Challenges of contraceptive adoption are confronted majorly by the method failures, once the prevalence of the contraception is nearly established in urban Uttar Pradesh. Low level of awareness about conceptions' mechanism and inefficient use of the reversible method attribute to higher casual sexual encounter and a false sense of security, leading to unwanted pregnancies and hence abortions.

Besides country-level interventions and investment in the FP, state-sponsored interventions and financing are desirable for enriching the quality of family planning care. To ensure the reproductive right of a woman, a series of necessary steps are needed to percolate adequate method information and competent use of both traditional and modern reversible methods. Along with this, a better regulatory mechanism is required to create awareness regarding safe abortions. Therefore, in addition to address the unwanted fertility rates in India's populous state, family planners need to focus on failure issues in more comprehensive manner. Besides elucidative findings, the study also suffers certain limitations. The first and foremost is related to the recall lapses regarding the monthly use of family planning methods collected in MLE survey. Second, in a country where majority of abortion is taking place in private health facilities, the number of abortions may be underreported. Also, the social and cultural stigma attached to the abortions in India may have significant effect on reporting pattern of incidences of cases. 


\section{Abbreviations}

MTP: Medical Termination of Pregnancy; FP: Family planning; CPR: Contraceptive prevalence rate; MLE: Measurement Learning and Evaluation; URHI: Urban Reproductive Health Initiatives; GFR: Gross failure rate; UP: Uttar Pradesh; SDGs: Sustainable Development Goals; AFT: Accelerated failure time

\section{Acknowledgements}

Not Applicable

\section{Authors' contributions}

AS conceived the study and performed statistical analysis. RM wrote the draft of the text. Prof KKS and PV made substantial contributions to drafting the manuscript. All authors read and approved the final manuscript.

\section{Funding}

The research has not received any financial grant from any organization or funding agency.

\section{Availability of data and materials}

The data used in this study are available upon request. Please see: Carolina Population Center Data Portal for the Measurement, Learning \& Evaluation project at: https://data.cpc.unc.edu/projects/14/view to request the data. Data are available for download after an approval of a restricted use application, which involves signing a data use agreement and providing brief information about intent of use (investigator information, research team information, and statement of purpose).

\section{Ethics approval and consent to participate}

Ethical approval was not required for this work as no new empirical data were collected.

\section{Competing interests}

The authors declare that they have no competing interests.

\section{Author details}

${ }^{1}$ Department of Statistics, Institute of Science, Banaras Hindu University, Varanasi, UP 221005, India. ${ }^{2}$ Centre for the Study of Regional Development (CSRD), School of Social Sciences, Jawaharlal Nehru University, New Delhi 110067, India. ${ }^{3}$ Global IT Centre, State Bank of India, Mumbai, Maharashtra 400023, India.

Received: 7 September 2019 Accepted: 7 May 2020

Published online: 03 June 2020

\section{References}

Agrahari, K., \& Mohanty, S. K. (2015). Traditional Methods Use and Pregnancy Termination in India. Social Science Spectrum, 1(3), 194-205

Ali, M., \& Cleland, J. (1995). Contraceptive discontinuation in six developing countries: a cause-specific analysis. International family planning perspectives, 92-97.

Ali, M. M., Marshall, T., \& Babiker, A. G. (2001). Analysis of incomplete durations with application to contraceptive use. Journal of the Royal Statistical Society: Series A (Statistics in Society), 164(3),549-63.

Basu, A. M. (1984). Ignorance of family planning methods in India: an important constraint on use. Studies in Family Planning, 15(3), 136-42.

Black, K. I., Gupta, S., Rassi, A., \& Kubba, A. (2010). Why do women experience untimed pregnancies? A review of contraceptive failure rates. Best Practice \& Research Clinical Obstetrics \& Gynaecology, 24(4), 443-55.

Bongaarts, J., \& Feeney, G. (1998). On the quantum and tempo of fertility. Population and development review, 271-91.

Bongaarts, J., \& Westoff, C. F. (2000). The potential role of contraception in reducing abortion. Studies in family planning, 31(3), 193-02

Bradley, S. E., Croft, T., \& Rutstein, S. O. (2011). The impact of contraceptive failure on unintended births and induced abortions: estimates and strategies for reduction. Calverton^ eMaryland Maryland: ICF Macro.

Cleland, J., \& Ali, M. M. (2004). Reproductive consequences of contraceptive failure in 19 developing countries. Obstetrics \& Gynecology, 104(2), 314-20.

Creanga, A. A., Acharya, R., Ahmed, S., \& Tsui, A. O. (2007). Contraceptive discontinuation and failure and subsequent abortion in Romania: 1994-99. Studies in family planning, 38(1), 23-34.

Curtis Siân, L., \& Hammerslough, C. R. (1995). Model further analysis plan: contraceptive use dynamics. Macro International Inc: Calverton.

Faúndes, A. (2010). Unsafe abortion-the current global scenario. Best practice \& research Clinical obstetrics \& gynecology, 24(4), 467-77.

Finer, L. B., \& Henshaw, S. K. (2006). Disparities in rates of unintended pregnancy in the United States, 1994 and 2001. Perspectives on Sexual and Reproductive Health, 38(2), 90-96.

Goldman, N., Pebley, A. R., Westoff, C. F., \& Paul, L. E. (1983). Contraceptive failure rates in Latin America. International Family Planning Perspectives, 50-57.

Government of India. (1971). The medical termination of pregnancy act (Act No. 34). New Delhi: Government of India

Government of India. (2002). The medical termination of pregnancy (amendment) act. New Delhi.

Government of India. (2003). The medical termination of pregnancy rules (amendment) act. New Delhi.

Government of India. (2016). Family Planning Division, MoHFW. Post Abortion Family Planning: Technical Update (p. 2016). New Delhi.

Gupte M., Bandewar S., \& Pisal H. (1997). Abortion needs of women in India: A case study of rural Maharashtra. Reproductive Health Matters,5 (9), 77-86. 
Hossain, M. B., \& Phillips, J. F. (1996). The impact of outreach on the continuity of contraceptive use in rural Bangladesh. Studies in Family Planning, 27(2), 98-106.

International Institute for Population Sciences (IIPS) and ICF. (2017). National Family Health Survey (NFHS-4), 2015-16: India. Mumbai: IIPS.

International Institute for Population Studies (IIPS) \& Macro International. (2007). National Family Health Survey (NFHS-3), 200506: India Volume I. Mumbai: IIPS.

Jain, A. K. (1989). Fertility reduction and the quality of family planning services. Studies in Family Planning, 20(1), 1-16.

Jain, A. K. (2017). Information about methods received by contraceptive users in India. Journal of Biosocial Science, 49(6), 798810.

Jejeebhoy, S. J. (1991). Women's status and fertility: successive cross-sectional evidence from Tamil Nadu, India, 1970-80. Studies in Family Planning, 22, 217-230.

Johnston, H. B. (2004). Abortion practice in India: a review of literature. Mumbai: Centre for Enquiry into Health and Allied Themes, Research Centre of Anusandhan Trust.

Johnston, H. B., \& Hill, K. (1996). Induced abortion in the developing world: indirect estimates. International Family Planning Perspectives, 22, 108-114 \& 137.

Jones, R. K. (2018). Reported contraceptive use in the month of becoming pregnant among US abortion patients in 2000 and 2014. Contraception, 97(4), 309-312.

Marston, C., \& Cleland, J. (2003). Relationships between contraception and abortion: a review of the evidence. International Family Planning Perspectives, 6-13.

Mathai, S. T. (1997). Making abortion safer. The Journal of Family Welfare, 43(2), 71-80.

Nanda, P., Achyut, P., Mishra, A., \& Calhoun, L. (2011). Measurement, Learning \& Evaluation of the Urban Health Initiative: Uttar Pradesh, India, Baseline Survey 2010. TWP-3-2011]. Chapel Hill, NC: Measurement, Learning \& Evaluation Project. 2011. Reference Source.

Oddens, B. J., \& Lehert, P. (1997). Determinants of contraceptive use among women of reproductive age in Great Britain and Germany I: demographic factors. Journal of Biosocial Science, 29(4), 415-435.

Polis, C. B., Bradley, S. E. K., Akinrinola, B., Tsuyoshi, O., Trevor, C., \& Susheela, S. (2016). Contraceptive failure rates in the developing world: an analysis of demographic and health survey data in 43 countries. New York: Guttmacher Institute.

Retherford, R. D., \& Choe, M. K. (1993). Statistical models for casual analysis. New York: Wiley.

Retherford, R. D., \& Roy, T. K. (2003). Factors affecting sex-selective abortions in India and 17 major states. Mumbai: National Family Health Survey Report No. 21.

Shah, I., \& Ahman, E. (2010). Unsafe abortion in 2008: global and regional levels and trends. Reproductive Health Matters, 18(36), 90-101.

Shekhar, C., Sundaram, A., Hussain, R., Pradhan, M. R., \& Kalyanwala, S. (2018). Unintended pregnancy, abortion and post abortion care in Uttar Pradesh, India-2015. New York: Guttmacher Institute.

Singh, A., Singh, K. K., \& Verma, P. (2016). Knowledge, attitude and practice GAP in family planning usage: an analysis of selected cities of Uttar Pradesh. Contraception and reproductive medicine, 1(1), 20.

Singh, S., Juarez, F., Prada, E., \& Bankole, A. (2019). Estimating abortion incidence: assessment of a widely used indirect method. Population Research and Policy Review, 1-30.

Singh, S., Remez, L., Sedgh, G., Kwok, L., \& Onda, T. (2018). Abortion worldwide 2017: uneven progress and unequal access abortion worldwide 2017: uneven progress and unequal access.

Singh, S., Shekhar, C., Acharya, R., Moore, A. M., Stillman, M., Pradhan, M. R., \& Sundaram, A. (2018). The incidence of abortion and unintended pregnancy in India, 2015. The Lancet Global Health, 6(1), 111-120.

Srivastava, A., Mahmood, S. E., Srivastava, P. M., Shrotriya, V. P., \& Kumar, B. (2012). Nutritional status of school-age children-A scenario of urban slums in India. Archives of public health, 70(1), 8.

Sundaram, A., Vaughan, B., Kost, K., Bankole, A., Finer, L., Singh, S., \& Trussell, J. (2017). Contraceptive failure in the United States: estimates from the 2006-2010 National Survey of Family Growth. Perspectives on Sexual and Reproductive Health, $49(1), 7-16$.

Tsui, A. O., McDonald-Mosley, R., \& Burke, A. E. (2010). Family planning and the burden of unintended pregnancies. Epidemiologic Reviews, 32(1), 152-174.

Wang, D., Yan, H., \& Feng, Z. (2004). Abortion as a backup method for contraceptive failure in China. Journal of Biosocial Science, 36(3), 279-287.

Westoff, C. (2012). Unmet need for modern contraceptive methods: DHS analytical studies no. 28 (pp. 1-45). Calverton: ICF International.

Westoff, C. F. (2005). Recent trends in abortion and contraception in 12 countries. DHS Analytical Studies No. 8. Calverton: ORC Macro.

Zhang, F., Tsui, A. O., \& Suchindran, C. M. (1999). The determinants of contraceptive discontinuation in Northern India: a multilevel analysis of calendar data. Chapel Hill: MEASURE Evaluation, Carolina Population Center, University of North Carolina at Chapel Hill.

\section{Publisher's Note}

Springer Nature remains neutral with regard to jurisdictional claims in published maps and institutional affiliations. 